\title{
ANALISIS KESELAMATAN DAN KESEHATAN KERJA PADA DEPARTEMEN SERVICE PT. MEGA DAYA MOTOR MAZDA JATIM DENGAN METODE 5 WHYS DAN SCAT
}

\author{
Yoniv Erdhianto \\ Jurusan Teknik Industri ITATS, J1. Arief Rachman Hakim 100, Surabaya \\ Email: yoniverdhianto@gmail.com
}

\begin{abstract}
This study focuses on the analysis of the application of OSH (occupational safety and health) in PT. Mega Daya Motor Mazda Jatim through observation of several accidents that occurred during the study. Where the general purpose of this study is as a reference for the reader, especially students to be able to analyze how the application of effective OSH in the company. The specific purpose of this research is to know the cause of accidents that occurred in the service department of PT. Mega Daya Motor Mazda Jatim and to prepare a work safety analysis (JSA) specifically for the workshop in an effort to improve OSH for the future. The research was conducted by qualitative approach based on secondary data in the form of observation report documents, questionnaires to workshop employees, accident investigation and photo of the incident about work accident. The techniques used to analyze the cause of the accident is 5 Whys and SCAT. With the 5 Whys method researchers are able to process field facts by repeatedly asking the same question of a problem that becomes a crucial factor, then sorting the cause or solution into clearer elements. To strengthen the results of the 5 Whys analysis, the researcher analyzed again using the SCAT method. SCAT provides a series of questions that can guide researcher to find the causes of accidents based on categories that have been made by the SCAT method that has a complete question.
\end{abstract}

Keywords: OSH (occupational safety and health), 5 Whys, SCAT

\begin{abstract}
ABSTRAK
Penelitian ini berfokus pada analisis penerapan K3 di PT. Mega Daya Motor Mazda Jatim melalui pengamatan kecelakaan yang terjadi selama studi berlangsung. Tujuan umum penelitian ini adalah sebagai referensi bagi pembaca, khususnya mahasiswa untuk dapat menganalisis bagaimana penerapan K3 yang efektif di perusahaan. Adapun tujuan khusus dari penelitian ini yaitu untuk mengetahui penyebab kecelakaan yang terjadi pada bagian pelayanan PT. Mega Daya Motor Mazda Jatim dan menyiapkan analisis keselamatan kerja (JSA) khusus untuk bengkel kerja dalam upaya meningkatkan K3 ke depan. Penelitian dilakukan dengan pendekatan kualitatif berdasarkan data sekunder berupa dokumen laporan observasi, kuesioner kepada karyawan bengkel, investigasi kecelakaan, dan foto kejadian kecelakaan kerja. Teknik yang digunakan untuk menganalisis penyebab kecelakaan adalah 5 Whys dan SCAT. Dengan metode 5 Whys, peneliti dapat mengolah fakta lapangan dengan berulang kali menanyakan pertanyaan yang sama tentang masalah yang menjadi faktor penting, kemudian menyortir penyebab atau solusi hingga menjadi unsur yang lebih jelas. Untuk memperkuat hasil analisis 5 Whys, peneliti menganalisis kembali dengan metode SCAT. SCAT menyediakan serangkaian pertanyaan yang bisa membantu peneliti untuk menemukan penyebab kecelakaan berdasarkan kategori yang telah dibuat dengan metode SCAT yang memiliki pertanyaan lengkap.
\end{abstract}

Kata kunci: K3 (keselamatan dan kesehatan kerja), 5 Whys, SCAT

\section{PENDAHULUAN}

Keselamatan dan kesehatan kerja merupakan hal yang penting bagi perusahaan karena dampak kecelakaan dan penyakit kerja tidak hanya merugikan tenaga kerja tetapi juga perusahaan, baik secara langsung maupun tidak langsung. Keselamatan kerja berarti proses merencanakan dan mengendalikan situasi yang berpotensi menimbulkan kecelakaan kerja melalui persiapan prosedur operasi standar yang menjadi acuan dalam bekerja [1]. 
Angka kecelakaan kerja di Indonesia tahun 2014 masih cukup tinggi. Tercatat 96.314 kasus dengan korban meninggal mencapai 2.144 orang dan mengalami cacat sebanyak 42 orang dengan perkiraan kerugian akibat kecelakaan mencapai Rp280 triliun per tahun. Kecelakaan kerja tidak hanya dapat menyebabkan kematian, kerugian materi, moril, dan pencemaran lingkungan, namun juga dapat mempengaruhi produktivitas dan kesejahteraan masyarakat.

PT. Mega Daya Motor Mazda merupakan salah satu perusahaan yang bergerak di bidang otomotif yang mendapatkan pengakuan resmi dari pemerintah Jawa Timur sebagai agen tunggal dalam menjual kendaraan bermotor dengan merek Mazda untuk seluruh wilayah Jawa Timur. Selain itu, PT. Mega Daya Motor Mazda bergerak dalam usaha importir suku cadang untuk mobilmobil merek Mazda dan juga memberikan jasa perawatan dan perbaikan kendaraan merek Mazda.

Salah satu cara yang dilakukan PT. Mega Daya Motor Mazda adalah dengan mengelola sistem K3 yang juga merupakan salah satu indikator keselamatan para karyawannya di dalam melakukan kegiatan kerja sehari-hari. Oleh karena itu, peneliti tertarik untuk mengadakan penelitian mengenai keselamatan dan kesehatan kerja (K3) di bengkel kerja yang terdapat di PT. Mega Daya Motor Mazda Jatim.

Tujuan penelitian ini yaitu mengetahui penyebab kecelakaan kerja yang terjadi di departemen service PT. Mega Daya Motor Mazda Jatim dan menyusun analisis keselamatan kerja (JSA) khusus untuk bengkel dalam upaya peningkatan K3 untuk masa yang akan datang.

\section{TINJAUAN PUSTAKA}

Menurut [2] pada pasal I, disebutkan bahwa tempat kerja ialah setiap ruangan atau lapangan, tertutup atau terbuka, bergerak atau tetap, dimana tenaga kerja bekerja atau yang sering dimasuki tenaga kerja untuk keperluan suatu usaha dan dimana terdapat sumber atau sumbersumber bahaya baik di darat, di dalam tanah, di permukaan air, di dalam air, di udara yang berada di wilayah kekuasaan hukum Republik Indonesia, yang ruang lingkupnya ditentukan oleh 3 (tiga) unsur, yaitu (1) tempat dilakukan pekerjaan bagi sesuatu usaha, (2) adanya tenaga kerja yang bekerja di sana, dan (3) adanya bahaya kerja di tempat tersebut.

Keselamatan dan kesehatan kerja (K3) merupakan instrumen yang memproteksi pekerja, perusahaan, lingkungan hidup, dan masyarakat sekitar dari bahaya akibat kecelakaan kerja. Perlindungan tersebut merupakan hak asasi yang wajib dipenuhi oleh perusahaan. K3 mencegah, mengurangi, bahkan menihilkan risiko kecelakaan kerja (zero accident). Penerapan konsep ini tidak boleh dianggap sebagai upaya pencegahan kecelakaan kerja dan penyakit akibat kerja yang menghabiskan banyak biaya (cost) perusahaan, melainkan harus dianggap sebagai bentuk investasi jangka panjang yang memberi keuntungan yang berlimpah pada masa yang akan datang.

Sedangkan definisi K3 menurut falsafah keselamatan kerja dapat diterangkan sebagai upaya dalam menjamin keadaan, keutuhan, dan kesempurnaan, baik jasmaniah maupu rohaniah manusia serta hasil karya dan budayanya, tertuju pada kesejahteraan masyarakat pada umumnya dan manusia pada khususnya. Pada [3], diberikan ketentuan mengenai kesehatan kerja dalam pasal 23 yang menyebutkan bahwa kesehatan kerja dilaksanakan supaya semua pekerja dapat bekerja dalam kondisi kesehatan yang baik tanpa membahayakan diri mereka sendiri atau masyarakat, dan supaya mereka dapat mengoptimalkan produktivitas kerja mereka sesuai dengan program perlindungan tenaga kerja. Higiene perusahaan dan K3 dapat dikatakan memiliki satu kesatuan pengertian yang merupakan terjemahan resmi dari Occupational Health dan diartikan sebagai lapangan kesehatan yang mengurusi problem kesehatan secara menyeluruh terhadap tenaga kerja. Menyeluruh maksudnya usaha-usaha kuratif, preventif, dan penyesuaian faktor menusiawi terhadap pekerjaanya.

\section{Tinjauan Penelitian Terdahulu}

Penelitian sebelumnya telah dilakukan [4]. Persamaan penelitian terdahulu dengan penelitian yang dilakukan oleh penulis adalah masalah yang diteliti, yaitu analisis kecelakaan kerja dengan menggunakan analisis 5 Whys \& SCAT. Sedangkan perbedaan penelitian terdahulu dengan penelitian yang dilakukan oleh penulis adalah objek yang dijadikan fokus penelitian, [5] berfokus 
pada perusahaan atau lembaga yang diteliti yaitu PT. X di Simenggaris Kalimantan Timur dan hanya berfokus pada satu kecelakaan yang terjadi pada saat itu. Sedangkan penelitian ini dilakukan pada PT. Mega Daya Motor Mazda Jatim berdasarkan kecelakaan yang sering terjadi selama 3 tahun terakhir dengan mengamati penerapan standar K3 di PT. tersebut dan analisis penyebab kecelakaan yang terjadi selama penelitian dilakukan.

\section{METODE}

Berdasarkan [5], tujuan menganalisis bukti-bukti adalah untuk mengidentifikasi peristiwaperistiwa yang mengarah pada insiden yang terjadi. Dengan mengidentifikasi penyebab insiden tersebut, perusahaan dapat berupaya mencegah insiden serupa terulang kembali. Dalam beberapa kejadian, ada beberapa faktor atau penyebab utama. Penyebabnya sering disebut sebagai akar penyebab, yaitu proses untuk mengidentifikasi apa yang sebenarnya salah dan sering membutuhkan penyelidikan mendalam melalui lapisan gejala atau efek dalam rangka untuk mengidentifikasi penyebab. Ada beberapa teknik untuk menganalisis bukti, antara lain:

\section{Whys}

Teknik ini dilakukan dengan berulang kali mengajukan pertanyaan yang sama dari suatu masalah, memilah penyebab atau solusi ke dalam elemen yang lebih jelas. Pada setiap tahap, ada beberapa jawaban dari pertanyaan why, yang menghasilkan struktur pohon hierarki. Keuntungan menggunakan teknik ini yaitu: (1) memungkinkan penyidik berbagi situasi; (2) memungkinkan pemeriksaan ulang bagian-bagian dari analisis sehingga dapat diubah, dihapus, atau ditambahkan setiap saat. Teknik ini mendukung cara berpikir acak/non-linear; dan (3) memungkinkan untuk tidak mengikuti beberapa cabang pohon, menganalisis hanya pada area yang lebih memungkinkan.

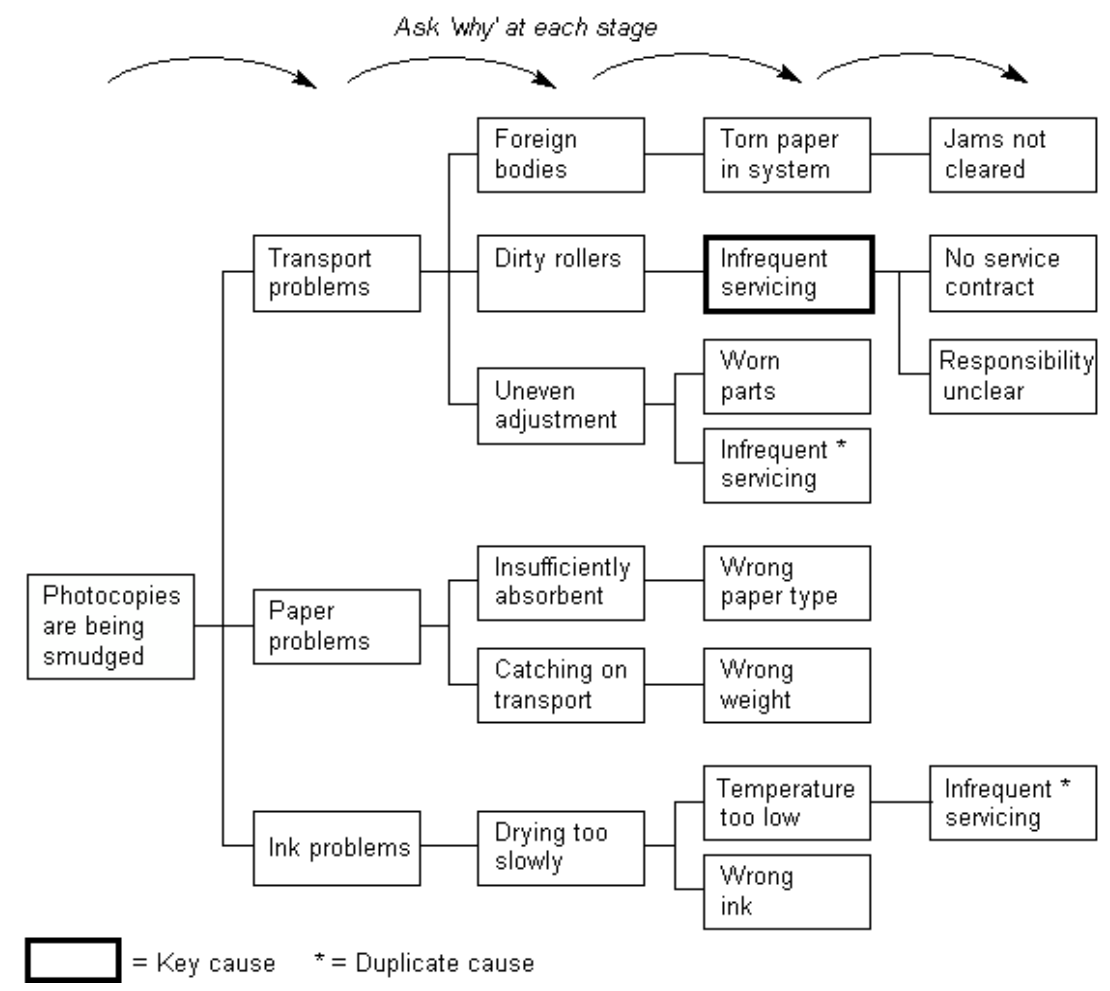

Gambar 1. Teknik 5 Whys [5]

\section{Systematic Cause Analysis Technique (SCAT)}

Teknik SCAT merupakan suatu cara menganalisis yang didasarkan pada lima langkah penyebab kesalahan yang dapat mengarahkan penyelidik pada kesimpulan melalui set pertanyaan. Pertanyaan ya/tidak ini didesain agar penyelidik dapat diarahkan ke pertanyaan berikutnya. 


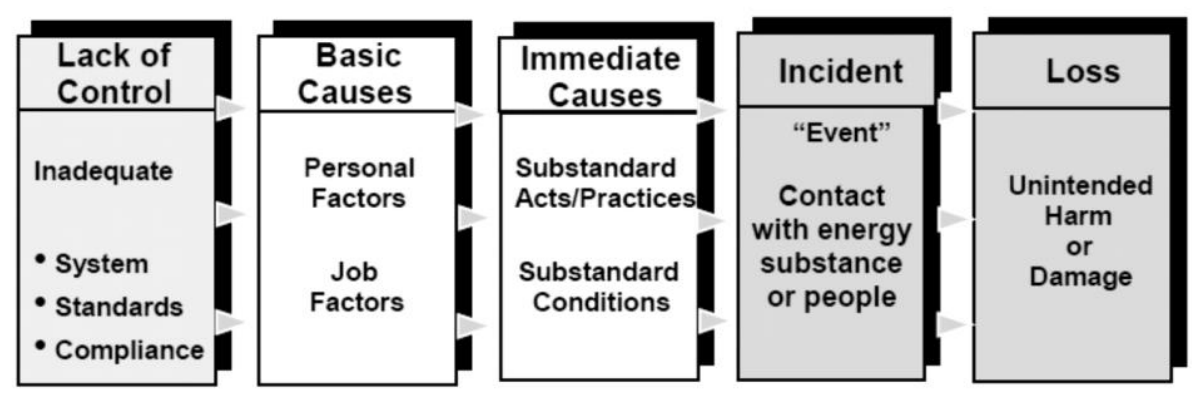

Gambar 2. SCAT Analysis [5]

\section{Langkah Pertama}

Dalam tahap ini, penyidik perlu mengumpulkan bukti yang terdiri atas 5 kategori, yaitu bukti saksi, posisi/lokasi, dokumen, parts evidence, dan reka ulang kecelakaan. Setelah bukti-bukti telah terkumpul, langkah ini membutuhkan penyelidik untuk mengevaluasi potensi kerugian jika kecelakaan tidak dapat dikendalikan. Ini adalah salah satu model investigasi kecelakaan yang mencoba mengenalkan prinsip-prinsip penilaian risiko ke penyelidikan. Akan tetapi, bagaimanapun potensi kerugian atau tingkat keparahan kecelakaan yang digunakan di sini hanyalah salah satu faktor yang dipertimbangkan dalam asesmen risiko tertentu.

\section{Langkah Kedua}

Langkah kedua dari penyelidikan ini, memerlukan penyidik untuk mengidentifikasi perangkat dari daftar, seperti peralatan, mesin, listrik, atau bahan peledak.

\section{Langkah Ketiga}

Pada langkah ketiga, penyidik diperlukan untuk mengidentifikasi apa yang disebut penyebab langsung dari dua daftar, satu untuk tindakan substandar dan yang lainnya untuk kondisi substandar. Daftar ini berisi masing-masing 21 dan 16 pilihan dan termasuk item seperti mengoperasikan peralatan tanpa izin dan penggunaan tidak aman/perlengkapan substandar, sistem peringatan tidak memadai dan substandar materi di bawah kondisi.

\section{Langkah Keempat}

Langkah keempat mengharuskan penyidik untuk mengidentifikasi apa yang disebut penyebab atau dasar kecelakaan. Pada langkah ini, sistem membagi penyebab/dasar menjadi tiga kategori yaitu faktor pribadi, faktor pekerjaan, dan faktor alam. Penyidik diperlukan untuk menjawab daftar 201 pertanyaan dalam 13 kategori.

\section{Langkah Kelima}

Dalam langkah ini, penyidik perlu mengidentifikasi tindakan kontrol yang diperlukan. Pertanyaanpertanyaan panduan mengajak penyidik kembali ke unsur-unsur sistem manajemen keselamatan dan menuntut penyidik untuk membuat rekomendasi.

\section{HASIL DAN PEMBAHASAN}

Beberapa kecelakaan yang tercatat selama penelitian berlangsung di PT. Mega Daya Motor antara lain kebakaran pada mesin mobil, gangguan pernapasan, luka pada kepala, terjatuh dari lift mobil saat kegiatan kerja berlangsung, dan tersiram oli mesin panas. Pengolahan data: 
Tabel 1. Klasifikasi biaya kecelakaan kerja

\begin{tabular}{llcc}
\hline Parameter Penilaian & Dampak Kecelakaan & $\begin{array}{c}\text { Dampak Kerugian } \\
\text { Material (Rp) }\end{array}$ & $\begin{array}{c}\text { Implementasi K3 } \\
(\%)\end{array}$ \\
\hline Terjadi kecelakaan ringan & $\begin{array}{l}\text { Luka ringan (tidak kehilangan } \\
\text { hari kerja) }\end{array}$ & $<100.000$ & $<70$ s.d. 100 \\
Terjadi kecelakaan sedang & $\begin{array}{l}\text { Luka berat atau dengan } \\
\text { perawatan intensif } \\
\text { Meninggal dunia atau cacat } \\
\text { Terjadi kecelakaan berat }\end{array}$ & $>1.000 .000$ & $>$ 40 s.d. 70 \\
\hline
\end{tabular}

\section{Analisis dengan Metode SCAT}

Berdasarkan hasil analisis dengan metode SCAT, didapat bahwa penyebab kecelakaan kerja: (1) kebakaran pada mesin mobil;

\begin{tabular}{|c|c|c|c|c|}
\hline $\begin{array}{c}\text { Kebakaran } \\
\text { mesin } \\
\text { mobil }\end{array}$ & $\begin{array}{l}\text { Api berasal } \\
\text { dari mesin } \\
\text { mobil yg } \\
\text { panas dan } \\
\text { tersiram } \\
\text { bensin }\end{array}$ & $\begin{array}{c}\text { Panasnya } \\
\text { mesin } \\
\text { mobil } \\
\text { (condition) } \\
\text { Menyiram } \\
\text { bensin pada } \\
\text { mesin } \\
\text { (action) }\end{array}$ & $\begin{array}{c}\mathrm{Ke}- \\
\text { cerobohan } \\
\text { operator }\end{array}$ & $\begin{array}{c}\text { Penerapan } \\
\text { SOP yang } \\
\text { benar. }\end{array}$ \\
\hline
\end{tabular}

Gambar 3. SCAT chart kebakaran mesin mobil

(2) sesak pernapasan;

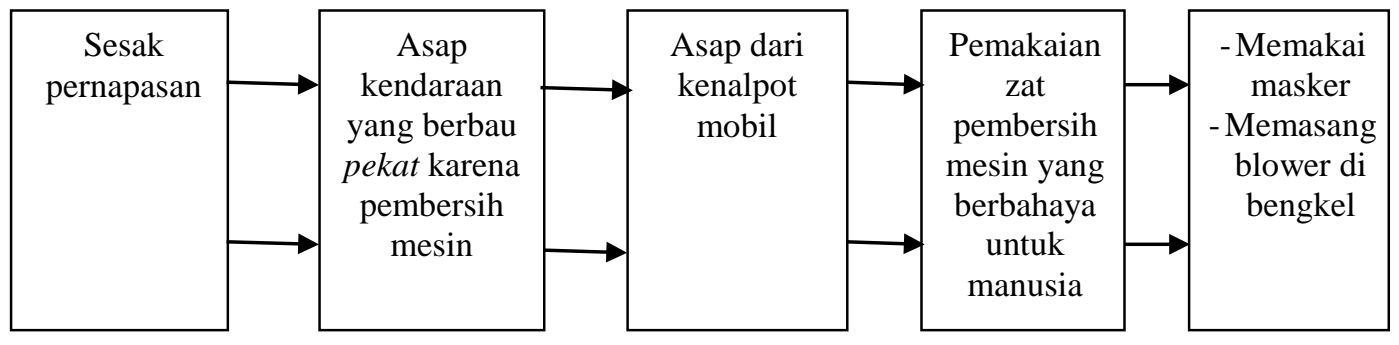

Gambar 4. SCAT chart gangguan pernapasan

(3) luka pada kepala;

\begin{tabular}{|c|c|c|c|c|}
\hline $\begin{array}{c}\text { Luka di } \\
\text { kepala }\end{array}$ & $\begin{array}{c}\text { Cideranya } \\
\text { kepala } \\
\text { karyawan saat } \\
\text { kerja }\end{array}$ & $\begin{array}{c}\text { Kepala } \\
\text { terbentur } \\
\text { benda kerja } \\
\text { (part } \\
\text { mobil) }\end{array}$ & $\begin{array}{c}\text { Tidak } \\
\text { adanya } \\
\text { pelindung } \\
\text { kepala } \\
\text { pada } \\
\text { pekerja }\end{array}$ & $\begin{array}{l}\text { Memakai } \\
\text { helm } \\
\text { (pengaman } \\
\text { kepala) }\end{array}$ \\
\hline
\end{tabular}

Gambar 5 SCAT chart kepala terbentur

(4) terjatuh dari lift mobil;

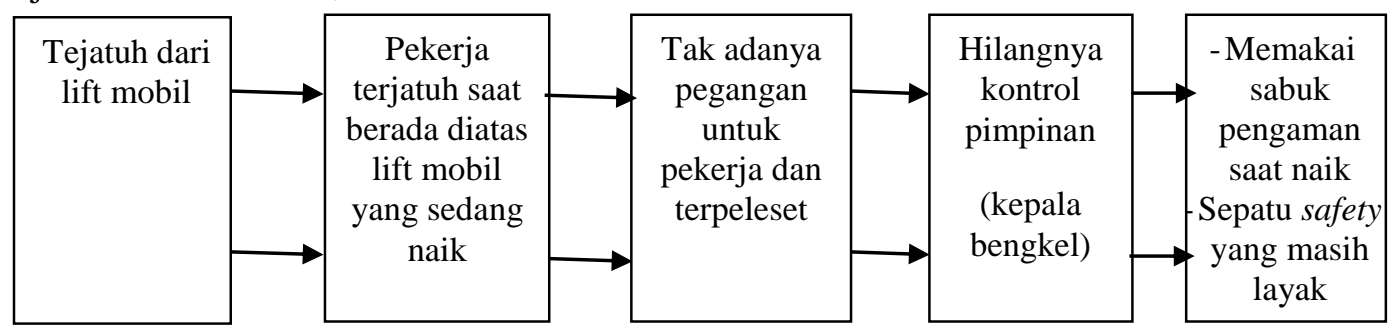

Gambar 6. SCAT chart terjatuh dari lift 
(5) tersiram oli mesin panas

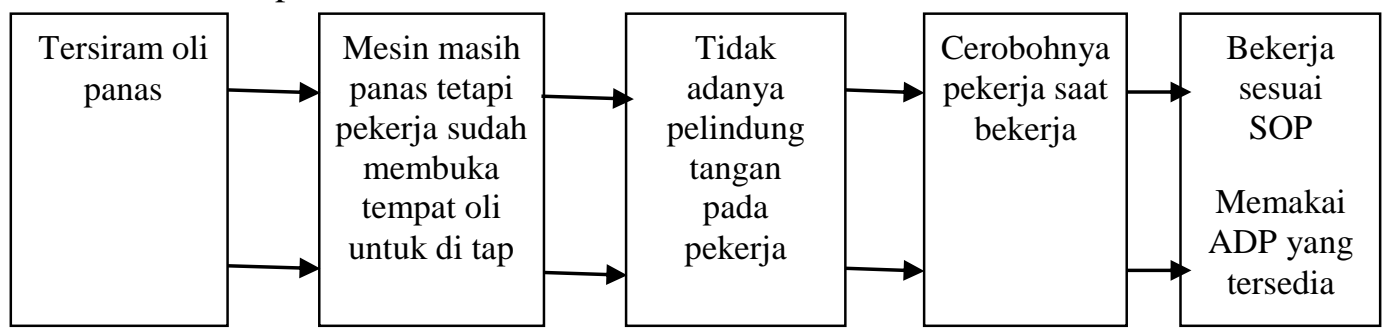

Gambar 7. SCAT chart tersiram oli mesin panas

Biaya-biaya yang dikeluarkan:

Tabel 2. Rincian biaya kecelakaan kerja yang dikeluarkan selama 1 bulan

\begin{tabular}{|c|c|c|c|c|c|c|}
\hline No. & Sebab Kecelakaan & $\begin{array}{r}\text { Hari Kerja } \\
\text { Hilang }\end{array}$ & $\begin{array}{l}\text { Jumlah } \\
\text { Korban }\end{array}$ & $\begin{array}{r}\text { Kerugian } \\
\text { Material (Rp) }\end{array}$ & $\begin{array}{l}\text { Akibat } \\
\text { Kecelakaan }\end{array}$ & $\begin{array}{l}\text { Keperluan } \\
\text { Biaya }\end{array}$ \\
\hline 1 & $\begin{array}{l}\text { Kebakaran mesin } \\
\text { mobil }\end{array}$ & 0 & 0 & 500.000 & $\begin{array}{l}\text { Kerusakan } \\
\text { komponen } \\
\text { mobil }\end{array}$ & $\begin{array}{l}\text { Penggantian } \\
\text { part yang rusak }\end{array}$ \\
\hline 2 & Bau asap mobil & 0 & 1 & 100.000 & Nafas sesak & $\begin{array}{l}\text { Pengobatan ke } \\
\text { RS }\end{array}$ \\
\hline 3 & Kepala terbentur & 0 & 1 & 50.000 & Kepala terluka & $\begin{array}{l}\text { Pengobatan luka } \\
\text { di kepala }\end{array}$ \\
\hline 4 & $\begin{array}{l}\text { Terjatuh dari lift } \\
\text { mobil }\end{array}$ & 0 & 1 & 20.000 & Kaki terkilir & $\begin{array}{l}\text { Memijatkan } \\
\text { kaki yang } \\
\text { terkilir }\end{array}$ \\
\hline 5 & $\begin{array}{l}\text { Tersiram oli } \\
\text { mesin panas }\end{array}$ & 1 & 1 & 100.000 & $\begin{array}{l}\text { Tangan kanan } \\
\text { melepuh }\end{array}$ & $\begin{array}{l}\text { Pemeriksaan } \\
\text { dan obat luka } \\
\text { bakar }\end{array}$ \\
\hline & Total & & & 770.000 & & \\
\hline
\end{tabular}

\section{Faktor Penyebab Kecelakaan Kerja}

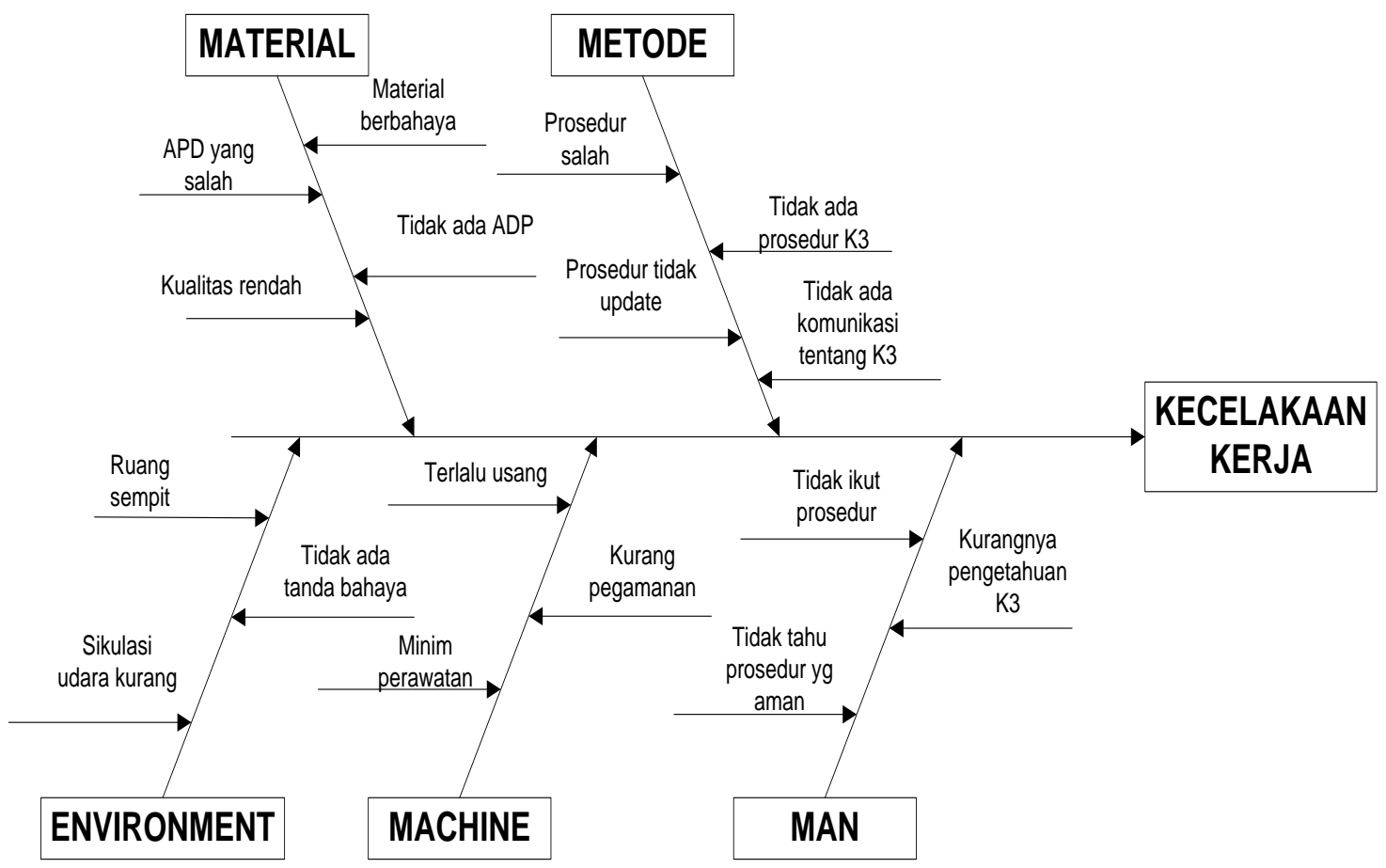

Gambar 8. Fishbone diagram faktor penyebab kecelakaan 


\section{Analisis dengan Metode 5 Whys}

Sebelum melakukan analisis penyebab kecelakaan dengan metode 5 Whys, peneliti membuat timeline kejadian dari tiap-tiap kasus kecelakaan yang terjadi.

\section{Kebakaran pada Mesin Mobil}

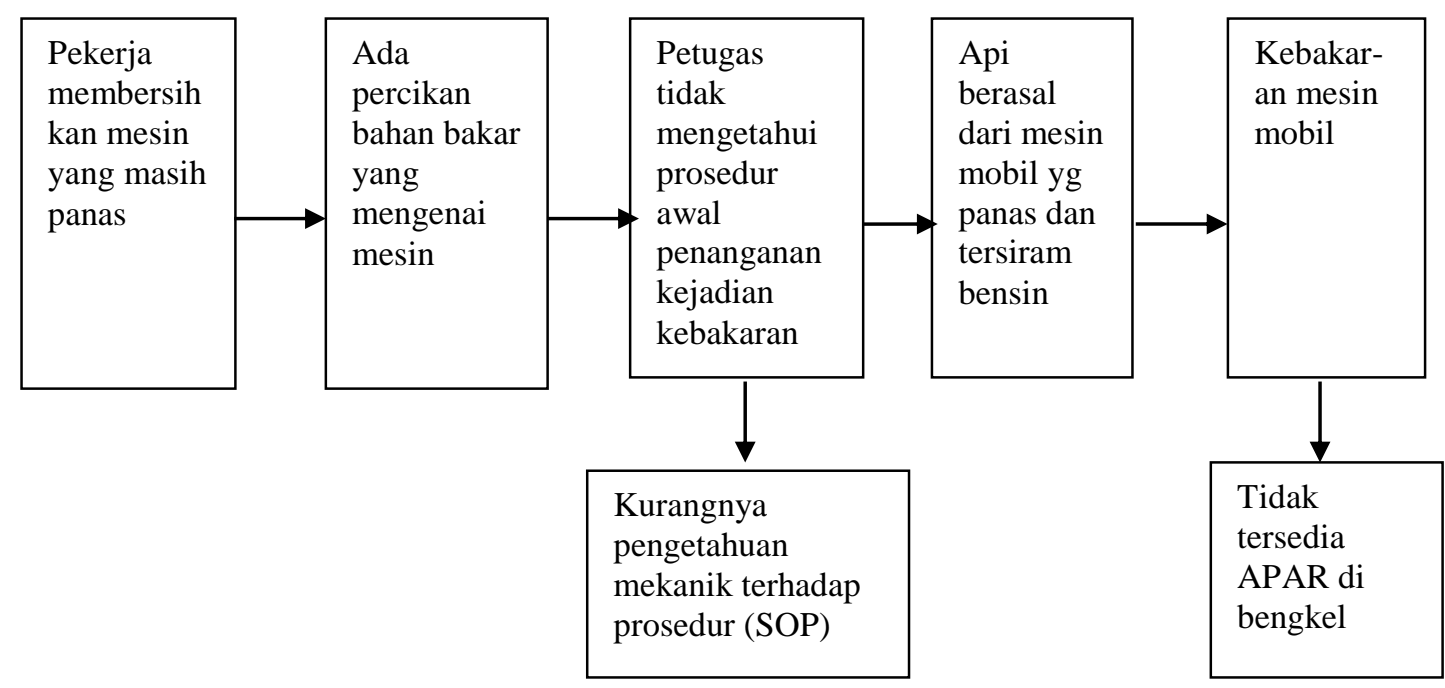

Gambar 9. Kebakaran mesin mobil

Kemudian, berdasarkan timeline kejadian, dilakukan analisis peristiwa untuk menentukan faktorfaktor kritis dari peristiwa kecelakaan ini.

\section{Peristiwa:}

1. Apabila mesin sudah dingin apakah kejadian kebakaran masih bisa terjadi? Tidak (faktor kritis).

2. Apabila pekerja mengetahui prosedur (SOP) dalam bekerja, apakah kejadian kebakaran mesin masih bisa terjadi? Tidak (faktor kritis).

3. Apabila tersedia APAR di sekitar bengkel, apakah kejadian kebakaran mesin masih bisa terjadi? Tidak (faktor kritis).

Jadi critical factor pada kejadian ini adalah:

1. Mesin masih panas tetapi pekerja tetap membersihkannya tanpa menunggu mesin dingin terlebih dahulu.

2. Pekerja tidak memahami SOP.

3. Tidak tersedia/hanya sedikit alat pemadam api ringan di sekitar bengkel.

Dari critical factor tersebut kemudian dilakukan analisis untuk menentukan akar penyebabnya. Analisis dilakukan dengan menggunakan metode 5 Whys. Adapun pertanyaan-pertanyaan yang muncul berdasarkan metode 5 Whys $(\mathrm{T}=$ tanya, $\mathrm{J}=$ jawab):

a. T : Mengapa mesin yang masih panas tetap dilakukan pembersihan oleh pekerja?

$\mathrm{J}$ : Karena karena kecerobohan pekerja.

$\mathrm{T}$ : Mengapa kecerobohan terjadi?

$\mathrm{J}$ : Karena kurangnya pengawasan dan kurang memahami prosedur.

$\mathrm{T}$ : Siapa yang bertanggung jawab terhadap pengawasan?

$\mathrm{J}$ : Kepala bengkel.

b. T : Mengapa terjadi kebakaran mesin mobil?

J : Karena mesin mobil masih panas dan terkena percikan bahan bakar.

$\mathrm{T}$ : Mengapa mesin yang masih panas terkena percikan bahan bakar?

$\mathrm{J}$ : Karena kecerobohan pekerja. 
$\mathrm{T}:$ Mengapa kecerobohan terjadi?

$\mathrm{J}$ : Karena kurangnya pengawasan dan kurang memahami prosedur.

$\mathrm{T}$ : Mengapa pekerja kurang memahami prosedur?

$\mathrm{J}$ : Karena kurangnya pelatihan dan sosialisasi K3.

c. T : Mengapa kebakaran mesin tidak segera dipadamkan?

$\mathrm{J}$ : Karena APAR tidak tersedia/jauh dari jangkauan.

$\mathrm{T}$ : Mengapa APAR tidak tersedia/jauh dari jangkauan?

$\mathrm{J}$ : Hanya ada sedikit APAR dan penempatannya jauh dari jangkauan pekerja bengkel.

$\mathrm{T}$ : Adakah prosedur dalam penanganan awal kebakaran?

$\mathrm{J}$ : Belum ada.

\section{Sesak Pernapasan}

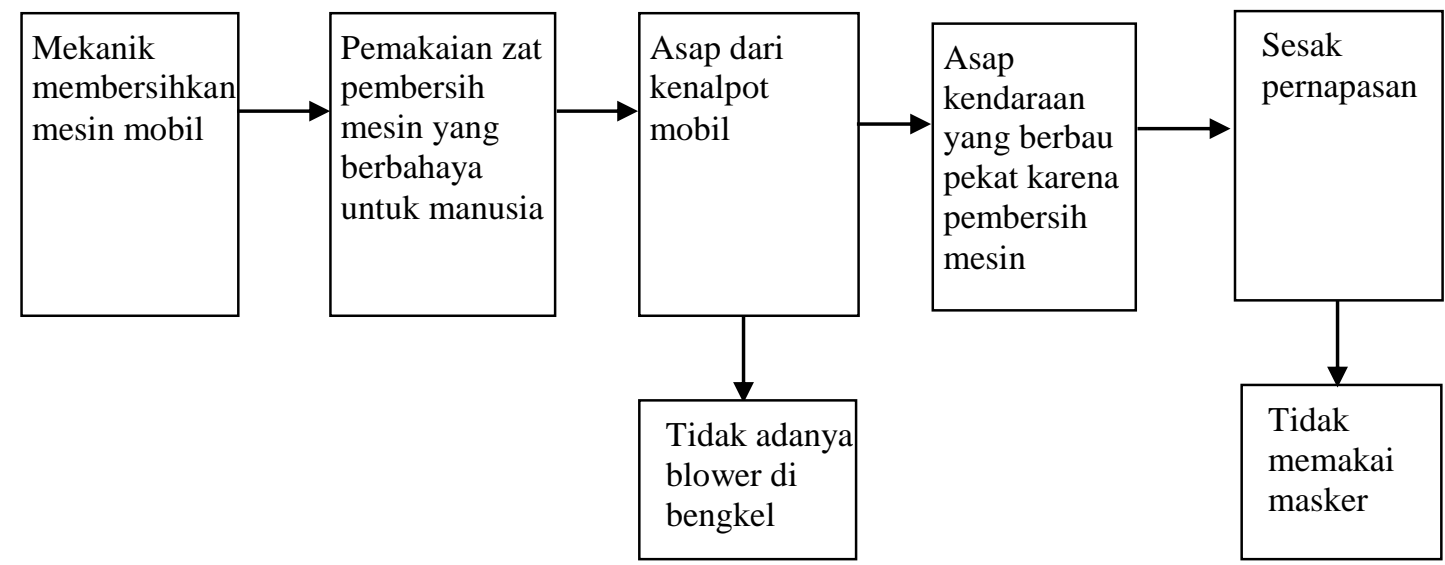

Peristiwa:

Gambar 10. Gangguan pernapasan

1. Apabila terdapat blower apakah kejadian asap yang terhirup pekerja masih terlalu banyak? Tidak (faktor kritis).

2. Apabila pekerja memakai masker apakah kejadian sesak napas masih bisa terjadi? Tidak (faktor kritis).

Jadi critical factor pada kejadian ini adalah:

1. Tidak adanya blower sehingga asap dari kendaraan mengganggu pekerja.

2. Pekerja tidak memakai masker saat bekerja.

Dari critical factor tersebut kemudian dilakukan analisis untuk menentukan akar penyebabnya. Analisis dilakukan dengan menggunakan metode 5 Whys. Adapun pertanyaan-pertanyaan yang muncul berdasarkan metode 5 Whys $(\mathrm{T}=$ tanya, $\mathrm{J}=$ jawab):

a. T : Mengapa asap dari kendaraan di bengkel terlalu banyak dan pekat?

$\mathrm{J}$ : Karena tidak adanya blower yang berfungsi menghalau/menghisap asap keluar.

$\mathrm{T}$ : Mengapa blower tidak dipasang di area bengkel?

$\mathrm{J}$ : Karena penanggung jawab bengkel belum mengajukan pengadaan blower.

$\mathrm{T}$ : Apa yang menghambat pengajuan blower di bengkel?

$\mathrm{J}$ : Penyusunan rancangan dan dasar pengajuan yang membutuhkan waktu.

b. T : Mengapa pekerja tidak memakai masker?

$\mathrm{J}$ : Karena kurangnya kesadaran terhadap kesehatan dan tidak memahami prosedur K3.

$\mathrm{T}$ : Mengapa pekerja tidak memahami prosedur K3?

$\mathrm{J}$ : Karena kurangnya pelatihan secara rutin mengenai K3.

$\mathrm{T}$ : Apakah perlu diadakan pelatihan $\mathrm{K} 3$ secara rutin?

$\mathrm{J}$ : Ya, perlu.

$\mathrm{T}$ : Apa yang perlu dilakukan untuk meminimalkan kejadian ini?

J : Perlu disediakan kotak P3K di sekitar bengkel. 


\section{Luka pada Kepala}

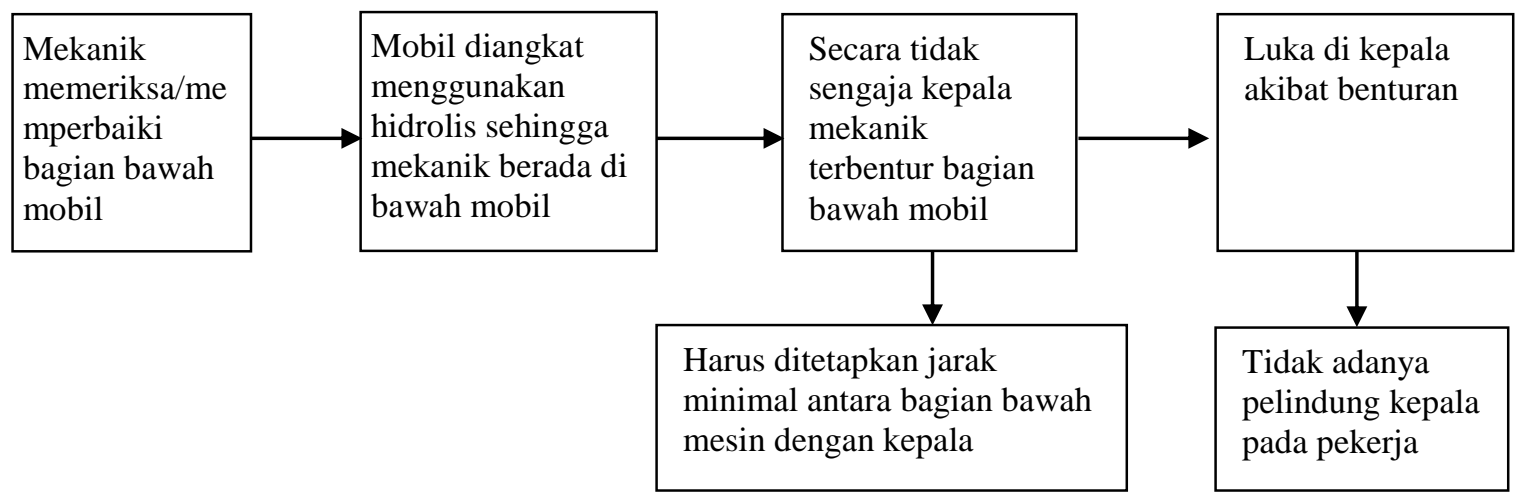

Peristiwa:

Gambar 11. Kepala terbentur

1. Apabila ditetapkan jarak minimal antara bagian bawah mesin dengan kepala apakah masih bisa terjadi kepala terbentur? Tidak (faktor kritis).

2. Apabila pekerja memakai pelindung kepala apakah masih bisa terjadi luka di kepala? Tidak (faktor kritis).

Jadi critical factor pada kejadian ini adalah:

1. Tidak adanya jarak minimal antara bagian bawah mesin dengan kepala.

2. Pekerja tidak memakai pelindung kepala (ADP).

Dari critical factor di atas kemudian dilakukan analisis untuk menentukan akar penyebabnya. Analisis dilakukan dengan menggunakan metode 5 Whys. Adapun pertanyaan-pertanyaan yang muncul berdasarkan metode 5 Whys $(\mathrm{T}=$ tanya, $\mathrm{J}=$ jawab):

a. T : Mengapa terjadi kepala terbentur ketika pekerja berada di bawah mobil yang berada di lift?

$\mathrm{J}$ : Karena pekerja tidak mengetahui jarak antara kepala dengan bagian bawah mobil.

$\mathrm{T}$ : Mengapa tidak mengetahui jarak antara kepala dengan bagian bawah mobil?

$\mathrm{J}$ : Karena tidak ditetapkan aturan berapa jarak minimal antara bagian bawah mobil dengan kepala pekerja.

b. T : Mengapa terjadi luka ketika kepala pekerja terbentur area bawah mobil?

$\mathrm{J}$ : Karena pekerja tidak memakai pelindung kepala.

$\mathrm{T}$ : Mengapa pekerja tidak memakai pelindung kepala?

$\mathrm{J}$ : Karena kurangnya pelatihan secara rutin mengenai K3.

$\mathrm{T}$ : Apakah perlu diadakan pelatihan $\mathrm{K} 3$ secara rutin?

$\mathrm{J}:$ Ya, perlu.

$\mathrm{T}$ : Apa yang perlu dilakukan untuk meminimalkan kejadian ini?

J : Perlu disediakan kotak P3K di sekitar bengkel.

\section{KESIMPULAN}

Berdasarkan hasil pengamatan, dapat disimpulkan:

1. Penerapan K3 pada PT. Mega Daya Motor masih belum sesuai dengan standar K3 yang berlaku. Dari hasil pengamatan menyatakan:

a. HSE plan dan instruksi kerja/SOP pekerjaan belum dilaksanakan secara konsisten.

b. Kurangnya pelatihan dan pengawasan dari PT. Mega Daya Motor dalam hal pelaksanaan prosedur keselamatan oleh mitra kerja.

c. Tidak memadainya standar kerja/prosedur keselamatan, antara lain tidak adanya prosedur penyimpanan peralatan keselamatan di bengkel.

d. Kurangnya kesadaran kepala bengkel dalam tanggung jawab HSE terhadap para pekerja. 
2. Solusi efektif untuk meminimalkan resiko dari potensi penyebab kecelakaan kerja yaitu:
a. Meningkatkan kesadaran pada pekerja akan pentingnya keselamatan kerja.
b. Mematuhi segala peraturan K3 demi keselamatan bersama.
c. Memberikan pelatihan kepada semua karyawan tentang K3.

\section{DAFTAR PUSTAKA}

[1] Suma'mur, P. K., 1996. Hygiene Perusahaan dan Kesehatan Kerja, Jakarta: Gunung Agung.

[2] Departemen Tenaga Kerja RI, 1999. Permenaker No. PER.05/MEN/1996 tentang Sistem Manajemen Keselamatan dan Kesehatan Kerja. Jakarta: Depnaker.

[3] Presiden RI, 1992. Undang Undang No. 23 Tahun 1992 Tentang: Kesehatan. Jakarta.

[4] Hermiyanti, D., 2012. Analisis Penyebab Kecelakaan Fatal Jatuh dari Kapal pada Transportasi Air Survei Seismik 2D PT. X di Simenggaris Kalimantan Timur Tahun 2010.

[5] Tasmania, H., 2010. Incident Management-Investigation Methodology Guide, HydroTasmania Procedure for Incident Management.

[6] Anton, T. J., 1989. Occupational Safety and Health Management. Singapore: Mc. Graw Hill.

[7] Brown, K. A., Willis, P. G., \& Prussia, G. E., 2000. Predicting Safe Employee Behavior in the Steel Industry: Development and Test of a Socio Technical Model. Journal of Operations Management, 18, pp.445-465.

[8] Hale, A.R., 2000. Culture's Confusions. Safety Science. 34(3), pp.1-14.

[9] Hagan, P. E., Montgomery, J. F., \& O'Reilly, J. T., 2001. Accident prevention manual for business and industry (12th ed.). Itasca, IL: National Safety Council.

[10] Ilo, 1989. Pencegahan Kecelakaan, Jakarta: Pustaka Binaman Pressindo.

[11] Lee, T. \& Harrison, K., 2000. Assesing Safety Culture in Nuclear Power Stations. Safety Science, 30, pp.61-97.

[12] Lee, T., 1998. Assessment.

[13] Ramli, S., 2010, Sistem Manajemen Keselamatan dan Kesehatan Kerja OHSAS 18001. Jakarta: Dian Rakyat.

[14] Ridley, J., 2004. Ikhtisar Kesehatan dan Keselamatan Kerja, Edisi Ketiga. Jakarta: Erlangga.

[15] Silalahi, B. \& Silalahi, R., 1995. Manajemen Keselamatan dan Kesehatan Kerja. Jakarta: Pustaka Binaman Pressindo.

[16] Simanjuntak, P. J., 1994. Manajemen Keselamatan Kerja, Jakarta: HIPSMI.

[17] Sudajana, P.J, 1996. Teknik Keselamatan Dan Kesehatan Kerja, Yogyakarta: Universitas Sanata Dharma.

[18] Sugiono, 1999. Statistik Untuk Penelitian. Bandung: Wahana Beta.

[19] Soeratno dan Arsyat. 1999. Metodologi Penelitian Untuk Ekonomi dan Basis. Edisi Revisi. Yogyakarta: UPP AMPYKPN.

[20] Umar, H., 1997. Metodologi penelitian: aplikasi dalam pemasaran. Jakarta: Gramedia Pustaka Utama.

[21] Ustadiyanto, R., 2001. Framework e-Commerce. Yogyakarta: ANDI.

[22] Wong P, Helsinger D, Petry J (2003). Providing the Right Infrastructure to Lead the Culture Change for Patient safety. Journal on Quality Improvement, 28: 363-72. 